\title{
A customer relationship management approach: Integrating the call centre with customer information
}

Received (in revised form): 5th December, 2000

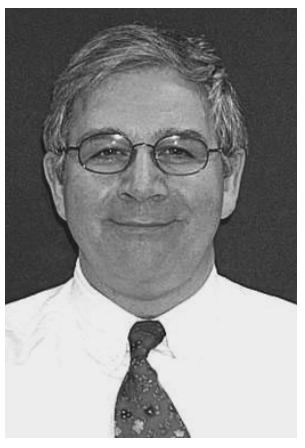

\section{Michael Meltzer}

has over 20 years' experience in financial services, telecommunication companies and information technology. He has authored many articles on financial services and computing using the customer-focused approach, and is a frequent speaker at industry conferences. With a Bachelor's degree in Marketing and a Master's degree in Business Administration, Michael is a valued member of DMR Consultants global practice. He specialises in CRM/e-business, benefits realisation and performance measurement.

Abstract In the age of the e-consumer and the need to manage customer relationships the marketing dilemma that many financial service providers (FSPs) face is how to get closer to their target market without investing more in bricks and mortar than clicks and mortar. This paper looks at how the call centre and the contact centre can be integrated as part of a multi-channel contact and touch-point management within a customer relationship management (CRM) solution based on a scaleable data warehouse (SDW) architecture as the infrastructure for competitive advantage.

The way customers are treated and their value to an organisation are reviewed with an emphasis on the customercentric view. The evolution of the call centre, contact centre and e-service are also discussed.

This paper explores how the CRM philosophy and SDW architectures can be effectively integrated and implemented and lead to success. There is also a need for clear marketing strategies that can be applied to web and wireless enabled call/contact centres. This is to support customer retention, cross-selling and up-selling opportunities to improve direct/continuous marketing campaigns, marketing to the segment of one and to put the organisation on the road to marketing one to one.

\section{INTRODUCTION}

It could be said that all customers are fickle. They seem to move their business to another financial service provider (FSP) even though their present provider has the best services and prices available. the best deal? The second question should be dealt with by competitive intelligence analysis, but the first is based on the need for relationship management and a true dialogue, and that is the basis of this paper. This paper looks at call centres as they make the transition to contact centres. And although call/contact centres are often used as customer service touch points and as a 
means of tele-selling to non-customers many FSPs, telecommunication companies and retailers use them to retain and increase their share of their current customers wallet rather than just acquire new customers. The call centre has become part of the customer relationship management (CRM) mythology. What was part of providing quality customer service and a means of creating dialogue with the customer has now been re-badged as being CRM spelt in bold loud letters. Although CRM does include customer call and contact management many of the call centre/contact management software vendors have managed to convince many unwary purchasers that all they need do is install their 'solution' and all their prayers will be answered. This paper will look at the evolution of the call centre and its integration with a data warehouse architecture (information on customer contact, billing, segmentation and so on) to serve as a focal point for the customercentric approach to CRM. The reasons for this new approach - that responds to customers' needs by providing high quality support, a dynamic marketing channel and a means of gathering soft data - will also be considered. 'Organisations are frankly frantic about providing more customer service', says Carter Lesher, VP and research director at Gartner Group, in many cases, it's what they're competing on: products have become commoditised, and customer service is one way to differentiate themselves'.

\section{RETENTION}

Customers are more expensive to replace than to retain. Some people put the cost of acquiring a customer as high as five to ten times more than to retain one.

Customers have been educated to expect a high level of service and a wide range of competitive products. Some FSPs offer a narrow range of products specifically targeting consumer segments (often called category killers or monoline providers) that have special service requirements and have been successful (with for example, credit cards, insurance, home loans etc.), but much depends on what customers expect. Failure to live up to their value expectations increases the risk of defection to another FSP, whether monoline or new entrant, that meets their perceived value needs. Studies by Reichheld and Sasser demonstrated that: 'As a customer relationship with a company lengthens, profits rise. And not just a little. Companies can boost profits by $100 \%$ by retaining just $5 \%$ more of their customers. ${ }^{1}$ Call centres have become a critical element in a company's armoury to retain customers by providing high-quality service, creating a dialogue with their customers and providing an opportunity to initiate proactive marketing. Yet their evolution into a mission critical financial services tool and telecommunication company (telco) provider differentiator has been far quicker in the USA than anywhere else, as has the move to integrate the data warehouse and on-line data store (ODS) to better target and respond to customer needs. The call centre enables a personal touch to be reintroduced if handled carefully. It is an opportunity to introduce high technology balanced by information and humanity. For a reiteration of the differences between acquisition and retention see Table $1 .^{2}$

\section{VOICE RESPONSE IS NOT ENOUGH}

Even if an 'enquirer' got through to a fully automated 'help desk' that had the latest integrated voice response (IVR) system, which in itself was seven levels deep, it is likely that they would give up after the fourth level, having been 


\begin{tabular}{ll}
\hline Retention & Acquisition \\
\hline Nurturing relationships & Acquiring potential relationships \\
Internal analysis & External research \\
Demographics and transactional history & Demographic profiles \\
Actual needs driven & Projected needs driven \\
Contacts must be personal & Contacts can be less personal \\
Accuracy required & Inaccuracy tolerated \\
Offer relationship driven & Offer driven \\
Offers must be integrated & Offers can be events \\
Supports reactivating & Supports assimilation \\
Synergistic with acquisition & Synergistic with retention \\
\hline
\end{tabular}

annoyed or frustrated and then tried unsuccessfully to get through several times before giving up. Was the company aware who they were or even that anyone had tried to get through at all? When companies upgrade from the complaints desk do they move to a customer-focused approach or is it an exercise in cost reduction, moving the customer away from the teller to some form of automation? Do they 'merely' replace humans with technology?

A number of major companies made this initial error when moving over to what are now known as 'call centres', but the move today is to use technology to support integrated marketing and provide quality customer services. The call centre is now viewed as one of the channels available for direct interaction with the customer. Moreover, many companies have gone back to using 'humans' as part of the equation better to serve the customer's and the company's needs. As the number of potential dialogue and touch points increase the need for the online data supported contact centre becomes apparent. The idea is that it will be able to support, manage and proactively build community with customers and potential customers. The contact centre is still in its infancy but is being rolled out quickly now its overall benefits and economics are being understood. But it is useful to consider the evolution of the call centre for a little longer.

The call centre has gained in importance as the use of telephones has spread and is set to gain momentum as countries deregulate their telecommunications industry and competition flourishes. The USA, where deregulation occurred some time ago and where the telephone is ubiquitous, is believed to be some 12-24 months ahead of Europe in its use of the telephone for: call centres, computer telephonic integration and, of course, the Internet. A simple definition of a call centre is any grouping of operatives and or automated voice response units (VRUs) that support customer contact functions over a telephone. The addition of computer support is also a prerequisite for any support unit to function adequately. Another definition of the call centre is a physical location (although there are some implementations of virtual call centres) where calls are placed or received in volume to enable sales, marketing, customer service, telemarketing, technical support or other specialised business activity.

\section{HISTORY}

Although help desks and call centres have existed for a long time, historically their only connection between the voice 
processing systems (PBX/ACD) and the data processing systems used by the services support operatives were the operatives themselves. It was in the late 1980s when computer telephonic integration (CTI) became commercially available, enabling linkage of the $\mathrm{PBX} / \mathrm{ACD}$ to a mainframe computer. Screen pop-ups and the ability to pass information and commands across this link became the latest technology boon to call centres. With the introduction of open systems, the adoption rate of client server environments has quickened. Adoption rates have not, however, been uniform, and this is so even in the USA where it is estimated that there are some 60,000 call centres in total, with banks alone accounting for over 1,300. Culture, geographies and available technologies have affected adoption rates, for example:

- the need for an Integrated Switched Digital Network (ISDN) and broadband network facilities to pass originating and dialled number information

- the complexity of systems implementation to create an integrated customer interaction site

- the cultural differences in doing business over the telephone

- the number and robustness of telephones and infrastructure available to the general populace

- the advent of third-generation telephony and other mobile practices.

\section{SERVICE LEADERSHIP}

Providing quality services to customers is a prerequisite to staying in business. Bad or inappropriate service in a highly competitive environment where the customer demands high-quality anytime, anyplace support, will see customers move to a competitor. The baseline for enhanced customer relationships rests on timely and accurate responses to inquiries and requests. Many customers also expect personal attention and often dislike voice response alone. The whole point of a call centre is to help retain the customer, and where appropriate, expand the relationship. Before exploring the other opportunities a fully integrated call centre offers, Joe O'Leary of Arthur Andersen advises that a business must 'provide the customer with the support and care they believe they deserve'. 'Together, these drive satisfaction - which drive loyalty, which drives profits. When customers wield the power of choice, providers respond'. Although price-based marketing is a short-term method to attract customers, over the long term customer care will build the loyalty necessary for continued success. Few businesses, however, have measured where the cost of providing excellent service meets the point of diminishing returns. Service alone can be a differentiator but as so many FSPs are striving to provide world-class services it is difficult to see how this differentiation will be achieved. For example, since Sanwa Bank of California put in branch call centres, calls to its toll-free 800 number have shot up, from $6 \mathrm{~m}$ in 1995 to $18 \mathrm{~m}$. Sanwa is tying together databases on mortgage loans, credit cards and regular accounts, enabling one call-centre teller to handle most of a customer's inquiries and 'make him feel like the only person in the world', says David Minor, a VP at the bank.

Further, a study by the Strategic Planning Institute has found historically that service leaders:

- charge on average 9 to 10 per cent more for their basic products and services

- grow twice as fast as their low-service competition

— improve market share on average by 
6 per cent per year. By contrast, low flyers lose market share by as much as 2 per cent annually

- have an average return on sales of 12 per cent compared to 1 per cent for the worst companies

\section{SALES AND CHANNELS}

From service support and care the call centre has grown into a cost-effective sales and distribution channel. This has led to the need for more sophisticated applications and even tighter integration between telephony and the organisation's computing systems. The latest findings from the Henley Centre (UK) would indicate, however, a wholesale decline in customers' perceptions of service by the telephone. In centralising operations and closing branches, many FSPs have lost the local, friendly feel that is all important when developing relationships with customers. And moving customers to centralised call centres has not helped. Many call centres only see a fraction of the relationship a customer may have with an FSP, this does not help cement a real relationship. The actionable information the SDW provides, integrated with the latest CIT can make the difference between success and failure when centralising support call centres. The data warehouse supports this tight coupling and goes on to supply much of the information needed to support the call centre giving that all important one, trusted view of the customer. At the same time, it also provides a means to take in the soft data (potential complaints and potential leads etc.) that the call centre accumulates on an on-going basis, so giving a 360-degree view of the relationship.

The information to provide operational support is customer/ relationship-based and must be available in real time. This is achieved by using a specialised data mart (DM). (The DM being a subset of the data warehouse). This type of data mart is often termed an on-line data store (ODS) particularly tuned to work as part of a real-time operational environment, but the reason ODS and SDW are required is found in the need to understand who a firm's customers are. All customers are not equal and a simple understanding of their value to an FSP proves this. If the ODS tackles the real-time interaction then the SDW can handle those vital analytics that support the business. Should all customers therefore be treated equally when some are more valuable than others? By knowing the value and potential value of customers an FSP can sell and provide services to one customer at a time. Even in countries where organisations are not allowed by privacy initiatives to use some of the data in their SDW they can look at customer profitability or view segments through anonymity slices. This use of data with user restrictions and anonymity requires changes to the SDW's logical data model. To understand why the data warehouse is now essential for the success of a proactive customercentric call centre it is useful to consider a current example that incorporates use of the Internet.

\section{AN EXAMPLE}

This example focuses on an FSP but could easily be extended to any other organisation that is willing to invest in the vision, technology and cultural changes needed.

A customer calls their FSP from home to initiate some simple payments and to enquire about their balance. The FSP's telephone system identifies the customer by the number used to dial in and the call is directed to a specific operative (because the customer is in a particular segment and is treated accordingly) who 
answers the call and greets the customer by name. The customer's usage profile and account balance has popped up on the workstation (this customer normally asks for a balance) plus a flashing prompt to inform the operative that there is a potential sales message to deliver. The operative has a single comprehensive view of this individual as an important customer of the FSP. The customer proceeds to make their payments and get their account balance. The operative puts their cursor on the prompt key and a dialogue appears. The customer's car loan will expire in three months and there is a special pre-approved loan on offer if they want to consider another. The customer would like some details quickly and asks if they can be e-mailed or faxed. The operative asks which method the customer would prefer - they request e-mail because it would be quicker. The operative tells the customer that they already have the e-mail address and the information is on its way. The customer is also informed that they could have someone call to talk them through the information or they could elicit a phone call by responding to the e-mail or even look further at the various summer offers on the FSP's website. If there is anything further of interest on the website all the customer has to do is type in their phone number and a specialist tele-consultant will call back.

\section{THE VISION OF THE CONTACT CENTRE}

The above scenario is being overtaken as customer preferences and technology changes. The cellphone has become ubiquitous and that leads to difficulty in monitoring callers. When the customer or prospect has a choice of media to contact the organisation the problems of tracking and management escalate. Messages can now be sent and received by media from land-line to wireless, from fax to letter and from SMS (messaging) to e-mail and, even, face-to-face. So the contact centre has been growing in status as the answer to these problems, but for many it is still a vision. On the back of an SDW architecture and middleware glue the vision is to build a centre logically centralised but potentially decentralised to support all customer and or prospect contact. Whereas the call centre can be seen as the centre for all voice-based contact, the contact centre will handle all channels: telephone, IVR, speech recognition and voice verification, voice over web (VOIP), e-mail, Web interaction, video interaction, fax, land mail and integrated message management (IMM). This can be further extended when the needs of the business-tobusiness (B2B) environment are considered.

In connection with the Web and WAP content provision and the opportunity for e-service should also be considered. The almost obvious view taking hold is that customers want to be treated consistently no matter what channel they use to communicate or do business with an organisation. To this end the SDW, ODS and a knowledge repository plus the management commitment and change management inside the organisation can be seen as vital to make it all successful. The current view of Gartner is that this requires an e-service suite that supports a central repository of information (maybe an SDW) that is also the knowledge base that enables a system to provide multiple views and presentations of the same information. The customer or prospect is central to this activity.

\section{THE FOCUS IS THE CUSTOMER}

The information held in the SDW can help identify the right customers to 
provide special services to and can profile customers' particular needs. Without this information drawn from the SDW and placed in the operational data mart (DM) for real-time, on-line support, much of the above would be difficult. Without the customer there is no business and it is this focus on the customer that drives the need for detailed information. The information the organisation has on its customers is its unique advantage in the marketplace. The value of information that can be bought in, that can be purchased by any organisation, only becomes apparent when it is integrated with a firm's existing information. This integration of data creates a unique differentiated set of information to be queried and mined. A firm's ability to understand its own customers is, however, hidden in the data it accumulates about their activities, and their likes and dislikes - not external inputs.

\section{TORONTO DOMINION}

To get at these data, turn them into actionable information and deliver them to the points of customer contact, many FSPs rely on their SDW. They also use the SDW to make customer information available FSP-wide for both branch and call-centre customer contact and for future detailed marketing analysis. An example of the need for different types of information can be gauged from the work Toronto Dominion (TD) is doing in Canada. 'The telephone's emergence and rising popularity as a primary FSP tool is a progressive result of the move towards greater convenience and increasing automation in every facet of our lives', says Mr Baillie of TD. 'Our customers have expressed their need for easy-to-use telephone banking services', adds Frank Van Nie, Director of Telephone Banking, at TD. 'We are answering their call with an expert team of banking agents who can now help them arrange mortgages and loans, contribute to RRSPs (savings plans), buy GICs (Guaranteed Investment Certificates), open an account, answer their financial questions, in addition to paying bills, transferring funds, and checking their account balance. Service is available in English, French, Cantonese and Mandarin'.

\section{A NON-FSP US WEST}

Described by Drury Jenkins as a closed loop CRM system, US West enhances its marketing effectiveness and cross-selling by integrating data from many sources and then supporting their outbound channel with scripts and offers that are pertinent to their customer base. John Barac (Marketing Decision Support Systems Director) said that in this SDW 'We have all kinds of data from all our different lines of business. We know the customers' behaviour and history. We also have external data, demographics, what kind of area they live in and the average income in that area. We have all the contact information'. Yet one of the most important uses of this integrated approach is in the area of inbound calls. Many have found that if customer problems can be satisfied on the inbound call they are more likely to sell more to a very receptive customer. 'On an inbound channel, if we get information, we try to capture that information for future use and we try to adjust our offer'. They use the information they capture as part of their knowledge base so they can learn about their customers' needs and alter future responses based on understanding of the customer.

\section{THE CHALLENGE}

The challenge that faces all organisations is how to get all the required 
information together to support the customercentric approach. In the early days some talked about clever interfacing and extraction software. This was only a small part of the answer. Information about the customer comes from many systems, divisions and channels. The information has to be available and trusted by its users. An SDW architecture that might include an ODS for real-time operational access and customercentric DMs enables the FSP to gain a holistic view of the customer. As the central SDW is the one version of the truth that can be trusted it is the resource that can unleash the power of the call/contact centre to create higher levels of service. It also enables organisations to create the perception of unique segment of one relationships. The reason an SDW is an important part of an integrated and effective call centre becomes obvious when FSPs try to answer these sorts of questions:

- what is the real value of their customer base - what is the difference between profitable and unprofitable customers

- how do they segment customers appropriately

- how do they increase their share of their spending power and what are the best ways to cross sell

- what are their preferences and can they use this knowledge to create unique segment-of-one offerings

- what do potential customers look like

- can they make predictions regarding their future purchases and then use that information to drive customer dialogue

- how can they retain the right customers

- what is the most effective delivery channel by particular service/product

- who is amenable to tele-consultative selling
- can they use permission marketing on their base and prospects?

\section{THE REAL VALUE OF CUSTOMERS}

If the value of a customer is known the decision can then be made about the sort of customer care and relationship to have with them to maintain or grow their profitability. This decision will have an effect on their treatment as a customer in the call centre. To do this it is necessary to look to at least two measures of customer value: their actual long-term value and their potential value. To begin this process of understanding the real value of a customer it is necessary to look at estimated customer lifetime value (LTV). The first step is to identify the sales of each product or service by some or all of the following: customer or number of accounts held or tenure. Finding out the frequency of customer defection and likelihood of switching will enable the FSP to better understand the cost to it in future revenue streams. By analysing the information the FSP has about the customer tenure it will be able to predict the length of time a customer is likely to stay (this equates to the lifetime in the equation). The FSP would then measure the future incomes, net of transaction costs and discounted by a rate the FSP chooses to get at their net present value. The equation can, of course, get more complex as more factors, such as propensity to defect, are introduced at a macro level, or as cost models are altered over time. The FSP could of course decide to assign a rank order to its customer base, based on the LTV as an approximation of true value. The idea is to identify those tiers of customers that are worth allocating resources to support and those that require different treatments. For example, by being able to identify those tiers that are marginal (borderline profitability) the 
FSP can allocate those specific resources to move them into profit. Note that without a good measure of real customer profitability LTV remains merely another approximation of customer value.

\section{HOW CUSTOMERS CAN SEGMENT THEMSELVES}

Customers and prospects tend to look for different things in any relationship they have with a vendor of any services or products. They also buy in different ways depending on their knowledge, lifestyles and education. The idea is to understand customers and what does and does not work for them. Much of the information about customer preferences can be gathered from the SDW and enriched from external sources and enlivened with clickstream data on an almost real-time basis for further analysis. Once the FSP knows the way they like to be treated and their value to the FSP it can provide the right level of quality services based on solid business reasoning. A good summary of how customers can be split in to buying segments appeared in Whiteley and Hessan's 'Customer-centred growth':

1. the transactional buy: little need for information or relationship (use of automated banking machines' PC-based services are a boon to these customers)

2. the relational buy: high relationship needs based on their need for personal emotional support throughout the purchase. (Purchase of complex insurance products and investments)

3. the information buy: they want information but no relationship as they know what they want but want information and an education (buying a mortgage, or discount brokerage services)
4. the partnership buy: they want a relationship and they want information as they have high affiliation needs and the desire to trust and partner with whoever they buy from (the purchase of personal equity plans, mutual funds and endowment policies). ${ }^{3}$

\section{USAGE PROFILES}

By knowing what products a customer takes, by default a firm knows what products they do not have. By modelling the ideal customer portfolio the firm can identify the range of products that would bring the most profit. It can also identify the ideal service and product usage pattern and, once again, profile customers against this. Are some customers more amenable to using telephone banking or billing enquiries rather than branches or shop fronts - who are they and what are they worth? A firm will then have a profile to test its customer base against and also have the basis on which to plan marketing campaigns. The campaigns will be designed to improve the company's share of wallet and each customer's profitability (including LTV). This technique, coupled with demographic and psychographic data, can also form the basis of the firm's segmentation rules. By using knowledge discovery (see the author's 'e-Mining Myth and Magic') a firm can begin to predict behaviours and make use of life triggers as part of its sales messages and outbound telemarketing campaigns.

\section{CHANNEL MANAGEMENT}

An integrated multi-channel SDW provides the means of knowing what channels customers use and prefer. The SDW collects all the transactional data from all the delivery channels and touchpoints. Once it is known what 
channels customers are using, the firm can look at their usage patterns. The patterns will quickly show whether a customer prefers certain channels to others. For an FSP some may want to use the branch or coffee shop, some will use only the call centre's telephone banking service and ATMs or even their new WAP portable. Still others will only make use of the new e-service the FSPs are beginning to offer. These new Internet-based tools and applications are designed to enable a higher level of self-service than hitherto available. They are being designed (according to Gartner) to enable the individual or organisation to interact with the FSP in a fashion that will integrate self-service, marketing and e-commerce. Yet another individual will transact all their business at a branch or set of ATMs in another part of the country, away from the branch that holds their current or chequeing account. An FSP could also collect information about the frequency of use by channel, by product, by value, by web click and so on. An understanding of preferences will also help when considering structural changes to a network, larger and more centralised call centres, new self-service terminals, Internet portals, refurbishment, or a radical alteration or closure of a branch, etc. By choosing certain channels rather than others (eg Internet broking, home banking and ATMs) customers themselves will map directly to an FSP's desire to lower the cost of delivery by their use of these channels. In addition the FSP can mine the clickstream generated on the Web. By monitoring and modelling the use of the Web greater behavioural insights are possible. The whole process of understanding the customer is in pursuit of managing the customer relationship for greater profit.

\section{RELATIONSHIP MANAGEMENT}

Customer relationship management is not dependent on just understanding the customer better but is about providing effective services and products that meet their perceived values. The delivery channels that meet their needs have to be fast, convenient, flexible and cost effective. A significant subset of the customer information that is available to a firm's knowledge workers must be available for use by customer facing staff, call-centre workstations, voice response units, ATMs, screen phones, decision support systems, WAP, the Internet portals and home banking applications for PCs or interactive television. A firm's

understanding of the customer's value to an organisation and their preferences enables it to devise treatments that will meet the customer's needs as well as the firm's need for continued profitable growth. Organisations rich in transactional data (telcos, FSPs and retailers) must capitalise on their unique informational advantage quickly. The faster they can get new services up and running to attract new customers, cross-sell or up-sell the right products/services to retain the right customers, whether through store fronts or in the e-space, the better their competitive advantage. This means the customer information and the technology infrastructure needed for product and service delivery have to be available today.

\section{A SUMMARY}

In summary, the reasons that the SDW architectures, call-centres and e-business are being integrated rest on an organisation's need to:

- increase revenue generation by having customer insight and understanding of dynamics of the cross-sell/up-sell opportunities. The 
idea is to increase revenue per customer contact by selling higher margin products through the call centre and, in the future, the contact centre. Then to further leverage the call-centre capabilities as a direct sales channel using consultative sales personnel. Each marketing campaign can be carried out at many levels, utilising direct mail, customer response advertisements, website offers, WAP and direct tele-selling. Each element, however, can be tied back to call-centre, touch point, Internet support and usage. The SDW has for many years been used as the base (trusted view of the customer) to guide and manage such marketing efforts. It is the SDW's integrative capabilities based on a self-renewing and adaptive architecture that makes it the ideal support mechanism for a dynamic multi-channel management that includes customercentric call/contact centres. Many believed the cost of building an integrated effective call centre could be a barrier to entry. The potential benefits and profits easily outweighed the costs and their ubiquitous nature today illustrates this

- increase customer satisfaction by improving the ability of the organisation to provide quick and accurate answers with the personalised attention customers have come to expect. The SDW architecture enables call-centre operatives to recognise high-value customers and provide them with a set of associated service levels. By better understanding customers' changing needs the call centre can build a relationship perception with each individual customer. When interacting with each customer, new customer information can be gathered that will enrich the underlying base data and improve the next interaction with that customer. This enrichment is useful in helping the FSP respond to customer needs, values and motivations thereby develop the new products and services the customers and potential customers will want

- strengthen competitive advantage by unlocking the power of detailed customer information and applying that power directly to the points of customer contact. This means providing the team players that come into contact with the customers with the same kind of information that the call centre, the Web, stores or branches use so that customers perceive an enterprise-wide approach to their relationship with the firm. The idea is to increase the company's share of the customer's wallet and the only way to do that is to know enough about the customer to provide them with the right services or products at the right time. By gathering information whenever there is a customer interaction, the company has the opportunity to gauge the success of its service levels and benchmark customer satisfaction.

The competitive environment is heating up for all types of company - now is not the time to do little and hope the waves of change will pass the firm by. In every country where the telephonic infrastructure is improving, the use of the Internet and call centres grow. The future holds the prospect of major contact centres being built and e-service being the norm. Additionally, the financial, telecommunication and retail services community cannot ignore the need for improved service levels and the need to retain/develop and acquire the right customers. The holistic approach is 
the use of the SDW architecture to integrate the disparate information systems that exist and the multiplicity of channels to and from the market. The call/contact centre are a major interface to the real world, they benefit from a tight coupling with the firm's knowledge repository, the data warehouse.

\section{References}

1 Reicheld, F. R. and Sasser, W. E. Jr Harvard Business Review, September-October (1990) and Reichheld, F. R. (1996) 'The loyalty effect'.

2 Source: McIntyre, J. M.

3 Whiteley, R. and Hessan, D. (1996)

'Customer-centred growth', Century Press.

(C) Michael Meltzer 2001 